\title{
Effects of Boron and Carbon on the Surface Tension of Molten Silicon under Precisely Controlled Oxygen Partial Pressure
}

\author{
Kusuhiro Mukai and Zhangfu Yuan \\ Department of Materials Science and Engineering, Faculty of Engineering, Kyushu Institute of Technology, \\ Kitakyushu 804-8550, Japan
}

\begin{abstract}
The surface tension of molten silicon is measured to be almost unchanged in the range of oxygen partial pressure, $P_{\mathrm{O}_{2}} \leqq 10^{-22} \mathrm{MPa}$ with the sessile drop method under precisely controlled the oxygen partial pressure. Then, the effects of boron concentration $\left(C_{\mathrm{B}} / \mathrm{mass} \%\right)$ and carbon concentration $\left(C_{\underline{C}}\right.$ /mass $\%$ ) on the surface tension were investigated with the same method under $P_{\mathrm{O}_{2}} \leqq 10^{-22} \mathrm{MPa}$. The results obtained are summarized as follows. The surface tension increases with increasing $C_{\underline{B}}$, and the maximum increase rate of the surface tension is about $30 \mathrm{mN} \cdot \mathrm{m}^{-1} \cdot\left(\text { mass } \% C_{\underline{B}}\right)^{-1}$ in the range of dilute boron concentration. The temperature coefficient of the surface tension, $(\partial \sigma / \partial T)_{C_{\mathrm{B}}}$, increases with increasing $C_{\underline{B}}$. Since dissolved boron from the BN substrate into molten silicon is below 0.054 mass $\%$ and the associated increase of the surface tension is below $1.5 \mathrm{mN} / \mathrm{m}$, the contamination from the BN substrate on the surface tension can be ignored. The relation between the surface tension and $C_{\underline{B}}$ indicates negative adsorption and is well described with Szyszkowski's equation. The surface tension remains almost constant even in carbon saturated silicon and $C_{\underline{C}}$ has almost no influence on $(\partial \sigma / \partial T) C_{\underline{C}}$ in the range of $C_{\underline{C}} \leqq 84$ mass ppm $\left(C_{\mathrm{c}, \text { sat }}\right.$ at $\left.1693 \mathrm{~K}\right)$.
\end{abstract}

(Received July 9, 1999; In Final Form November 12, 1999)

Keywords: surface tension, molten silicon, sessile drop method, oxygen partial pressure, boron, carbon, temperature

\section{Introduction}

Impurity distributions in silicon single crystals must be made as homogeneous as possible to fabricate ultra-largescale-integrated circuits. The oxygen of around 10 mass ppm $\left(10^{18}\right.$ atoms $\left./ \mathrm{cm}^{3}\right)$ was dissociated from a quartz crucible into molten silicon and is transferred into the crystal through the melt convection in a Czochralski (CZ) method. Thus, the melt convection must be understood and controlled to obtain crystals with a homogeneous oxygen distribution. Several types of flow, such as natural forced and the surface tension induced (Marangoni) may be enhanced in CZ systems during crystal growth. Marangoni convection is thought to be a main cause of oxygen transfer into crystals. Therefore, understanding the flow, especially Marangoni flow that is originated by spatial distribution of the surface tension of molten silicon should be clarified.

In $\mathrm{CZ}$ crystal growth, the dopant such as $\mathrm{B}, \mathrm{P}, \mathrm{As}$ and $\mathrm{Sb}$ is already contained in the polycrystalline starting material or is added to the silicon melt. It is known that the oxygen concentrations in $\mathrm{CZ}$ silicon are affected by the doping elements. ${ }^{1,2)}$ Carbon impurity in the silicon crystal produced by $\mathrm{CZ}$ method is introduced by carbon heaters or holders during $\mathrm{CZ}$ crystal growth via the silicon melts. The carbon impurity in silicon affects both oxygen precipitation and oxygen donor formation. $^{3,4)}$

The authors ${ }^{5,6)}$ have examined the effect of oxygen and temperature on the surface tension of molten silicon in the range of oxygen partial pressure, $P_{\mathrm{O}_{2}}$, from $10^{-22}$ to $10^{-19} \mathrm{MPa}$ by the sessile drop method. Relations between the temperature coefficient of the surface tension and $P_{\mathrm{O}_{2}}$ or the oxygen concentration in silicon $\left(C_{\underline{0}} /\right.$ mass $\left.\%\right)$ were fairly described quantitatively. The surface tension steeply decreases with increasing the $P_{\mathrm{O}_{2}}$. While in the range of $P_{\mathrm{O}_{2}} \leqq 10^{-22} \mathrm{MPa}$, the change of the surface tension has a tendency to becomes moderate. In order to detect precisely the effect of $C_{\underline{\mathrm{B}}}$ and $C_{\underline{\mathrm{C}}}$ on the surface tension, $P_{\mathrm{O}_{2}}$ in the atmosphere must be kept in an extremely low range where its influence on the surface tension is so small that the change in the surface tension due to the change in $P_{\mathrm{O}_{2}}$ during experiment can be neglected. Thus, this study confirmed the extent of $P_{\mathrm{O}_{2}}$ dependence of the surface tension in the condition of $P_{\mathrm{O}_{2}}$ lower than $10^{-22} \mathrm{MPa}$ and then the effect of $C_{\underline{\mathrm{B}}}$ and $C_{\underline{\mathrm{C}}}$ on the surface tension was investigated under the $P_{\mathrm{O}_{2}}$ where the influence of $P_{\mathrm{O}_{2}}$ on the surface tension is neglected, that is, in the condition of $P_{\mathrm{O}_{2}}$ lower than $10^{-22} \mathrm{MPa}$.

\section{Experimental Procedure}

\subsection{Apparatus}

The experimental apparatus consisted of $\mathrm{LaCrO}_{3}$ heating element furnace, a gas purifier, oxygen sensor, a photographic system and a digital system (computer). In order to maintain air-tightness of the reaction chamber, a double tube structure was adopted in the study. The reaction tubes were made of high purity alumina $\left(99.8 \% \mathrm{Al}_{2} \mathrm{O}_{3}\right)$. The outer tube is $50 \mathrm{~mm}$ in external diameter, $42 \mathrm{~mm}$ in internal diameter and $700 \mathrm{~mm}$ in length, and the inner tube is $37 \mathrm{~mm}$ in external diameter, $30 \mathrm{~mm}$ in internal diameter and $800 \mathrm{~mm}$ in length. Both ends of the reaction tube are sealed by water-cooled stainless caps. The temperature was measured with a $20: 40 \mathrm{Pt}-\mathrm{Rh}$ thermocouple, which was set directly under the boron nitride substrate, The maximum temperature for the furnace is $1923 \mathrm{~K}$. The temperature was controlled by a PID digital program controller.

The droplet shape of molten silicon was taken using a camera connected with a telephotographic lens by a bellows. The focal distance must be constant in all the experiments to fix the magnification of the photographed image. The focal distance was present in the position of infinity and the focus was 
Table 1 Chemical composition of $\mathrm{CZ}$ silicon and additions.

\begin{tabular}{clcc}
\hline Sample & Si & O & B \\
\hline CZ silicon & 99.999 mass $\%$ & $\approx 10$ mass ppm & $\leqq 5$ mass ppm \\
\hline Boron lump & $B \geqq 99.8$ mass $\%$ & \\
\hline Graphite powder & Fixed carbon $>99.6$ mass $\%$, Volatile $<0.15$ mass $\%$, Ash $<0.2$ mass $\%$ & \\
\hline
\end{tabular}

adjusted by changing the distance between the molten droplet and the camera fixed on a mechanical table, which can be moved three dimensionally.

The argon gas was passed through an Ar gas purifier and further deoxidized by magnesium chips heated at around $823 \mathrm{~K}$. The oxygen partial pressure in argon gas, $P_{\mathrm{O}_{2}}$, was controlled below $10^{-22} \mathrm{MPa}$ that is below $P_{\mathrm{O}_{2} \text {, sat }}$ in equilibrium with $\mathrm{SiO}_{2}$ (s) by the aid of a gas deoxidized purifier and a tightly sealed furnace made of double alumina tubes. $P_{\mathrm{O}_{2}}^{\text {out }}$, that is, $P_{\mathrm{O}_{2}}$ of Ar gas exhausted from the reaction chamber and $P_{\mathrm{O}_{2}}^{\text {in }}$, that is, $P_{\mathrm{O}_{2}}$ of $\mathrm{Ar}$ gas before introducing into the heating furnace were measured with an oxygen sensor of $\mathrm{ZrO}_{2}-\mathrm{CaO}$ solid electrolytes using a three-way cock, respectively.

\subsection{Procedure}

$\mathrm{CZ}$ silicon was employed as the base liquid for all composition of materials prepared. The composition of $\mathrm{CZ}$ silicon single crystals and additions (boron and carbon) are shown in Table 1. The cylindrical CZ silicon (about $1.83 \mathrm{~g}$ ) was polished with sandpaper to remove any surface oxide and cleaned with acetone using an ultrasonic automatic washer. The high purity boron nitride $(99.5 \% \mathrm{BN})$ plate $(25.7 \mathrm{~mm} \times 25.7 \mathrm{~mm} \times$ $2.5 \mathrm{~mm}$ ) was used as a substrate in the experiment. The BN substrate was washed with ethanol, dried and used without touching the surfaces, in order to avoid any possible contamination.

As shown in Fig. 1, the silicon sample containing boron or carbon was set on the upper surface of the BN substrate, and the horizon of the substrate was adjusted by two water levels. After the sample was placed into the inner alumina reaction tube of furnace by alumina support, the system was sealed and evacuated by a vacuum pump. Then, introduction of argon gas into the reaction chamber and evacuated was repeated three times. After that, the system was heated to experimental temperature in an argon gas atmosphere. The total flow rate of argon was maintained at $0.16 \mathrm{~L} / \mathrm{min}$ and the total pressure was held constant at $0.1 \mathrm{MPa}$ in all the experiments.

The photographs of the droplet of molten silicon were taken every $5 \mathrm{~min}$. The measurement time was $60 \mathrm{~min}$ for one experimental run. In order to obtain the values in the equilibrium state, the results measured in the latter $30 \mathrm{~min}$ were adopted.

According to Rotenberg's method, ${ }^{7)}$ the surface tension of molten silicon was calculated from the image contour of the droplet, which was input into a computer with a digitizer, by determining the curve with best fit between the numerical solution to the classical Laplace's equation and experimentally measured points. The magnification was determined by a picture of a standard steel ball $(10 \mathrm{~mm}$ in diameter) taken with

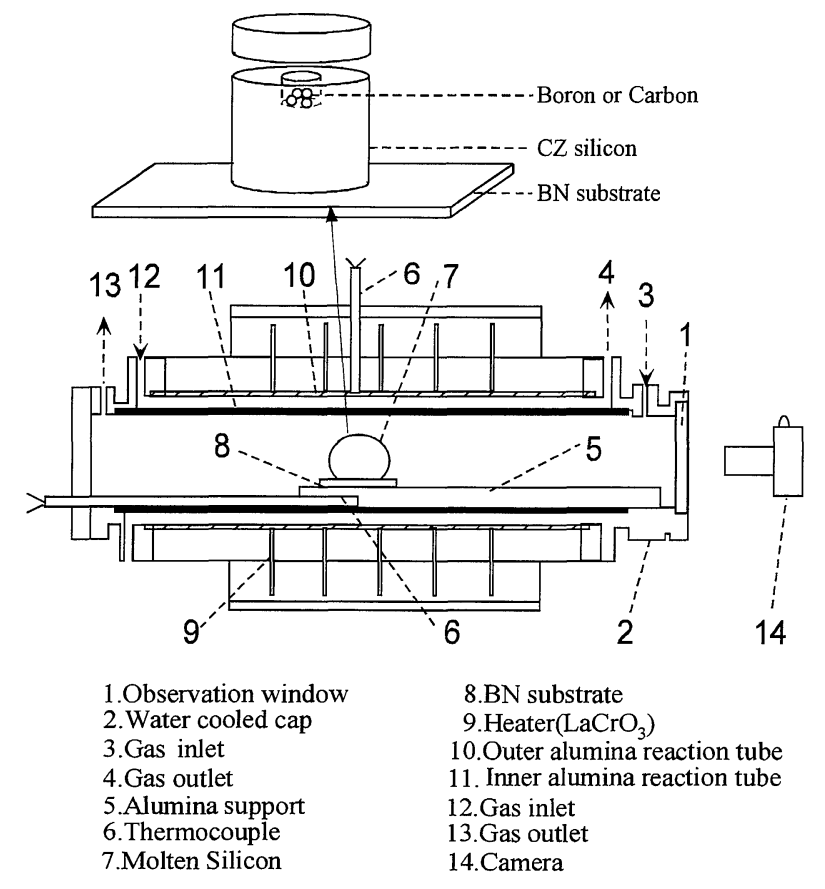

Fig. 1 Schematic diagram of experimental apparatus.

the same camera and in the same focal distance. The density of $\mathrm{Si}-\mathrm{B}\left(C_{\mathrm{B}} \leqq 2.35\right.$ mass $\left.\%\right)$ system as a function of temperature and boron concentration can be written as follows:

$$
\begin{aligned}
\rho\left(\mathrm{Mg} \cdot \mathrm{m}^{-3}\right)= & \left(2.52-3.07 \times 10^{-2}\left[C_{\underline{B}} / \text { mass } \%\right]\right) \\
& -\left(3.32-0.457\left[C_{\underline{B}} / \text { mass } \%\right]\right. \\
& \left.+0.105\left[C_{\underline{B}} / \text { mass } \%\right]^{2}\right) \times 10^{-4}(T-1687)
\end{aligned}
$$

Equation (1) obtained by a modified sessile drop method ${ }^{8)}$ was used for determining the surface tension of the $\mathrm{Si}-\mathrm{B}$ system. The density of molten silicon within saturated carbon concentration obtained in the study ${ }^{8)}$ is in agreement with the density of pure molten silicon. The measurement error was estimated to be $\pm 2 \%$ in the surface tension and $\pm 0.5 \%$ in the contact angle. ${ }^{9)}$

The boron concentration in silicon was analyzed by radiofrequency inductively coupled plasma (I.C.P.) emission spectrometry and carbon concentration in silicon by the combustion-IR absorption method.

\section{Results and Discussion}

\subsection{Effect of $\boldsymbol{P}_{\mathrm{O}_{2}}$ in argon gas}

As shown in Fig. 2, the change of the surface tension with the oxygen partial pressure is very small in the range of 


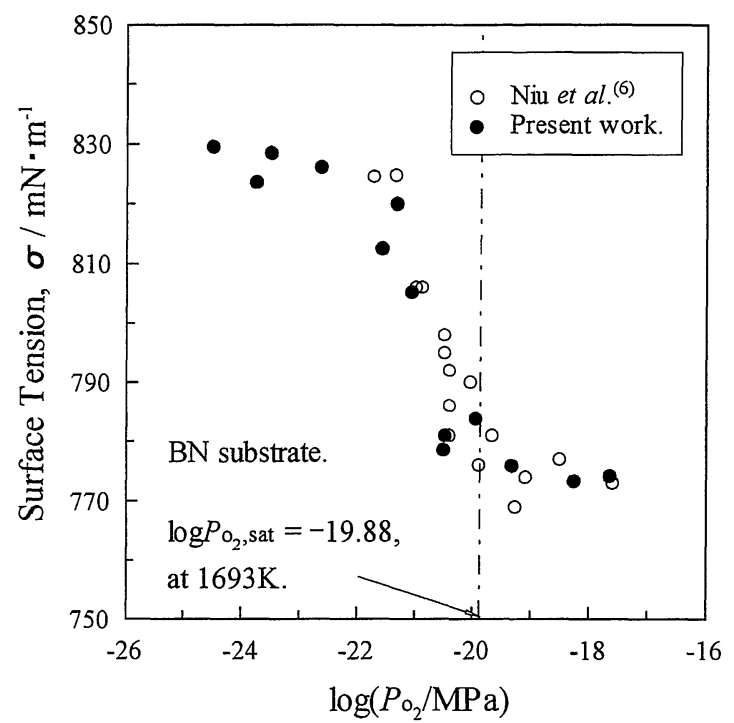

Fig. 2 Effect of the oxygen partial pressure in argon on the surface tension of molten silicon.

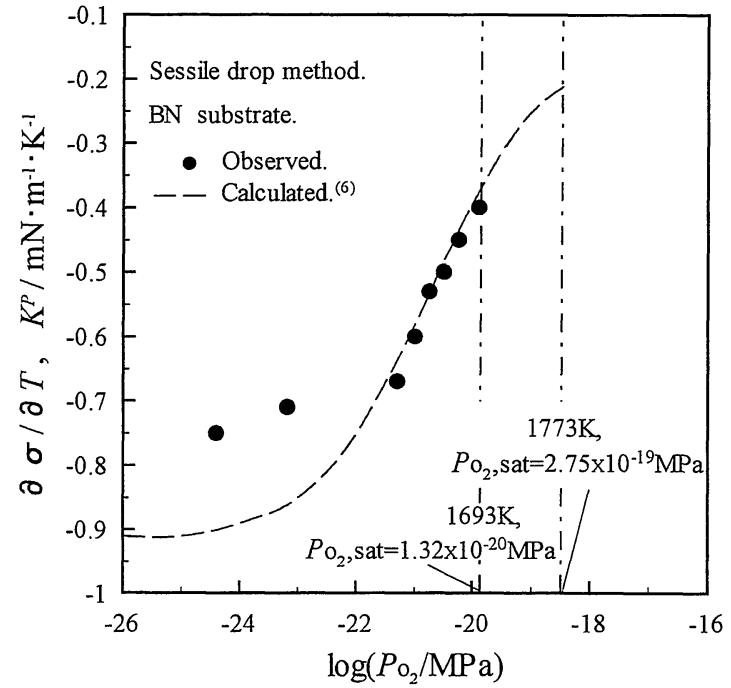

Fig. 3 Temperature coefficient of the surface tension of moldten silicon as a function of oxygen partial pressure of argon gas.

$P_{\mathrm{O}_{2}} \leqq 10^{-22} \mathrm{MPa}$. The surface tension decreases remarkably with increasing the oxygen partial pressure in the range of $P_{\mathrm{O}_{2}}$ from $5 \times 10^{-22}$ to $10^{-19} \mathrm{MPa}$, which is consistent with previous results obtained by the same apparatus and method. ${ }^{6,10)}$

As shown in Fig. 3, the temperature coefficient of the surface tension, $K^{P}=(\partial \sigma / \partial T)_{P_{\mathrm{O}_{2}}}$, is minus and increases with increasing the oxygen partial pressure. $(\partial \sigma / \partial T)_{P_{\mathrm{O}_{2}}}$ at $P_{\mathrm{O}_{2}}=10^{-24} \mathrm{MPa}$ is equal to about $-0.75 \mathrm{mN} \cdot \mathrm{m}^{-1} \cdot \mathrm{K}^{-1}$ and then $(\partial \sigma / \partial T)_{P_{\mathrm{O}_{2}}}$ gradually increases with increasing the oxygen partial pressure up to $5 \times 10^{-22} \mathrm{MPa}$. $(\partial \sigma / \partial T)_{\mathrm{P}_{2}}$ steeply increases with increasing the oxygen partial pressure in argon gas in the range of $P_{\mathrm{O}_{2}}$ from $5 \times 10^{-22}$ to $10^{-20} \mathrm{MPa}$.

$P_{\mathrm{O}_{2} \text {,sat }}$ shown in Fig. 2 or Fig. 3 is the equilibrium oxygen partial pressure in $\mathrm{SiO}_{2}(\mathrm{~s})-\mathrm{Si}(\mathrm{l})-\mathrm{O}_{2}$ system and can be calculated from $\Delta G^{\circ}=-952700+203.8 T(\mathrm{~J} / \mathrm{mol}){ }^{11)}$

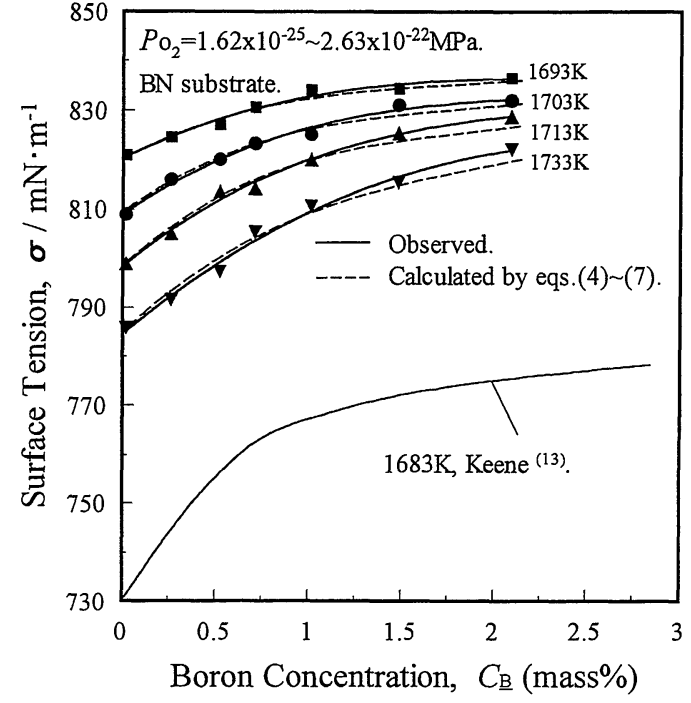

Fig. 4 Effect of boron concentration on the surface tension of Si-B system.

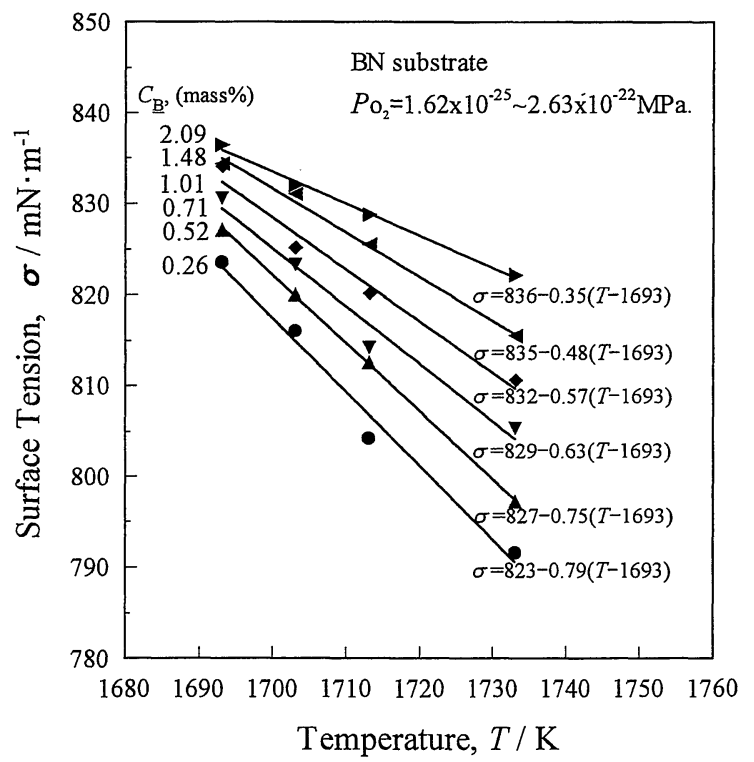

Fig. 5 Temperature dependence of the surface tension of molten silicon with various boron concentrations.

\subsection{Effect of $C_{\underline{B}}$ on the surface tension}

The surface tension of $\mathrm{Si}-\mathrm{B}$ system was determined in the condition of $P_{\mathrm{O}_{2}} \leqq 10^{-22} \mathrm{MPa}$ and $C_{\underline{\mathrm{B}}}$ lower than the saturated boron concentration (about 3.2 mass $\%{ }^{12)}$ ). Figure 4 shows results obtained in this study and those by other researchers. ${ }^{13)}$ The surface tension increases with increasing $C_{\underline{B}}$, and the maximum increase rate of the surface tension in the range from 1693 to $1773 \mathrm{~K}$ is evaluated to be about $30 \mathrm{mN} \cdot \mathrm{m}^{-1} \cdot\left(\operatorname{mass} \% C_{\mathrm{B}}\right)^{-1}$ from the slope of $\sigma-C_{\mathrm{B}}$ relation at $C_{\mathrm{B}}=0$ (Fig. $4,1773 \mathrm{~K}$ ). Additionally, as temperature becomes higher, the increase rate of the surface tension with boron concentration is higher.

Figure 5 shows temperature dependence of the surface tension of $\mathrm{Si}-\mathrm{B}$ system with various boron concentrations. The temperature coefficient of the surface tension, $K^{\mathrm{B}}=$ $(\partial \sigma / \partial T)_{C_{B}}$, is from -0.79 to $-0.35 \mathrm{mN} \cdot \mathrm{m}^{-1} \cdot \mathrm{K}^{-1}$ and in- 


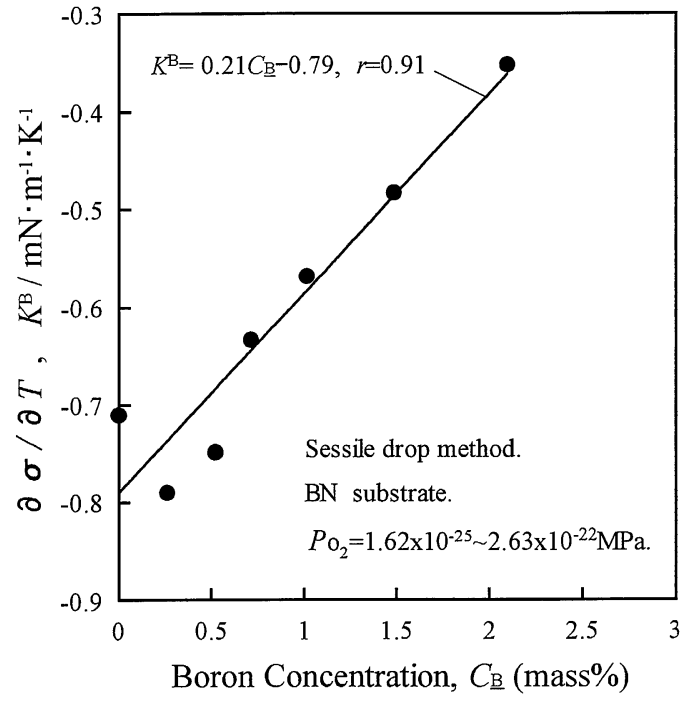

Fig. 6 Temperature coefficient of the surface tension as a function of boron concentration in silicon.

creases with increasing $C_{\mathrm{B}}$ as shown in Fig. 6. The decrease rate of the surface tension with temperature is lower as $C_{\underline{B}}$ becomes higher.

\subsection{Equation of the surface tension and $C_{\mathrm{B}}$}

Szyszkowski ${ }^{14)}$ derived an empirical relation to account for the effect of surface-active elements on the surface tension of liquid iron in a binary melt. Belton ${ }^{15)}$ modified this equation and presented it in a more usable form, by combining the Gibbs adsorption isotherm with the Langmuir isotherm:

$$
\sigma=\sigma^{\circ}-R T \Gamma_{i}^{\circ} \ln \left(1+K_{i} a_{i}\right)
$$

where $\sigma$ is the surface tension $(\mathrm{mN} / \mathrm{m}), \sigma^{\circ}$ is the surface tension of the pure metal $(\mathrm{mN} / \mathrm{m}), R$ is gas constant $(8.2056 \times$ $\left.10^{7} \mathrm{mN} \cdot \mathrm{K}^{-1} \cdot \mathrm{mol}^{-1}\right), \Gamma_{i}^{\circ}$ is the saturated surface excess concentration of the surface active component $i\left(\mathrm{~mol} / \mathrm{cm}^{2}\right), K_{i}$ is the adsorption coefficient of component $i$ and $a_{i}$ is the activity of species $i$ in solution.

$\Gamma_{i}^{\circ}$ can be determined by calculating the slope of the surface tension to the logarithm of the solute activity curve at high activities of solute according to the Gibbs adsorption equation.

$$
\Gamma_{i}=-(1 / R T)\left(\mathrm{d} \sigma / \mathrm{d} \ln a_{i}\right)
$$

where $\Gamma_{i}$ is the surface excess concentration $\left(\mathrm{mol} / \mathrm{cm}^{2}\right)$.

$\mathrm{d} \sigma / \mathrm{d} \ln a_{i}$ is minus $\left(\Gamma_{i}>0\right)$, which means positive adsorption; $\mathrm{d} \sigma / \mathrm{d} \ln a_{i}$ is plus $\left(\Gamma_{i}<0\right)$, which means negative adsorption. There have been a lot of reports relating to studies of positive adsorption. For example, Ogino et al., ${ }^{16)}$ Takeuchi et al. ${ }^{17)}$ and Zhu et al. ${ }^{18)}$ have concluded that the influence of surface-active species such as $\underline{\mathrm{O}}$ and $\underline{\mathrm{S}}$ on the surface tension of liquid iron is described with eqs. (2) and (3). But there have been little reports relating to negative adsorption. Monma and Suto ${ }^{19)}$ measured the surface tension of substitutionary binary alloy system, and concluded that the change of surface tension in a binary alloy system occurs in coincidence with the liquid line of phase diagram. This means that the surface tensions of the melt will increases when higher surface tension (higher

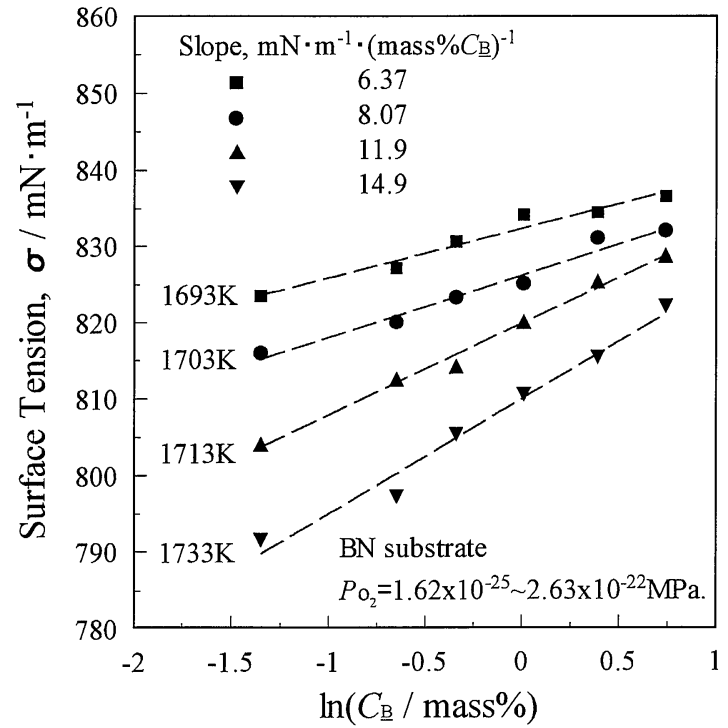

Fig. 7 Relation between the surface tension of $\mathrm{Si}-\mathrm{B}$ system and $\ln \left(C_{\underline{B}} /\right.$ mass $\left.\%\right)$.

melting point) elements are added into lower surface tension (lower melting point) elements. This is in conformity with the results shown in Fig. 4.

The relation between the surface tension of $\mathrm{Si}-\mathrm{B}$ system and $\ln \left(C_{\mathrm{B}} /\right.$ mass $\left.\%\right)$ is shown in Fig. 7. Since the each slope of the broken lines in the range of $C_{\underline{B}}=0.26 \sim 2.09$ mass\% in Fig. 7 shows almost constant, the saturated surface excess $\Gamma_{\mathrm{B}}^{\circ}$ can be evaluated from the slopes as follows: $-4.59 \times 10^{-11}$, $-5.77 \times 10^{-11},-8.47 \times 10^{-11}$ and $-1.05 \times 10^{-10} \mathrm{~mol} / \mathrm{cm}^{3}$ at $1693,1703,1713$ and $1733 \mathrm{~K}$, respectively. $\sigma^{\circ}$ was obtained by extrapolating the solid line in Fig. 4 to $C_{\underline{B}}=0$. Substituting $\Gamma_{\mathrm{B}}^{\circ}, \sigma^{\circ}, T$ and actual data into eq. (2), $K_{\mathrm{B}}$ can be calculated using the least square method.

Since the activity coefficient of boron at $X_{\mathrm{B}}=0.052$ $\left(C_{\mathrm{B}}=2.09\right.$ mass\%) is calculated to be 0.21 , assuming the regular solution of Si-B alloy $\left(R T \ln \gamma_{\mathrm{B}}=\alpha\left(1-X_{\mathrm{B}}\right)^{2}\right)$ at $1693 \mathrm{~K}$ and using $\left.\gamma_{\mathrm{B}}^{\circ}=0.18^{20}\right)\left(\gamma_{\mathrm{B}}^{\circ}\right.$ is the activity coefficient of boron in silicon at $\left.C_{\underline{\mathrm{B}}} \rightarrow 0\right)$. $f_{\mathrm{B}}$ can be calculated to be 1.13 from $f_{\mathrm{B}}=\left(\gamma_{\mathrm{B}} / \gamma_{\mathrm{B}}^{\circ}\right)\left(1-X_{\mathrm{B}}+X_{\mathrm{B}} M_{\mathrm{B}} / M_{\mathrm{Si}}\right)$ $\left(M_{\mathrm{B}}\right.$ and $M_{\mathrm{Si}}$ are the atomic weight of boron and silicon, respectively). Therefore, the activity of boron in the range of $C_{\mathrm{B}} \leqq 2.09$ mass\% approximately obeys Henry's law $\left(a_{\mathrm{B}}=\right.$ $\left.f_{\mathrm{B}} C_{\underline{\mathrm{B}}} \approx C_{\mathrm{B}}\right)$. Relation between the observed surface tension and boron concentration can be well described with eqs. (4)(7).

$$
\begin{array}{ll}
\sigma=821+6.37 \ln \left(1+4.49 C_{\underline{\mathrm{B}}}\right), & 1693 \mathrm{~K} \\
\sigma=809+8.07 \ln \left(1+6.84 C_{\underline{\mathrm{B}}}\right), & 1703 \mathrm{~K} \\
\sigma=799+11.9 \ln \left(1+4.40 C_{\underline{\mathrm{B}}}\right), & 1713 \mathrm{~K} \\
\sigma=785+14.9 \ln \left(1+3.81 C_{\underline{\mathrm{B}}}\right), & 1733 \mathrm{~K}
\end{array}
$$

The results calculated with eqs. (4)-(7) (the broken lines in Fig. 4) are in agreement with observed results.

The relation between $C_{\underline{B}}$ and the surface tension were measured in the condition of $P_{\mathrm{O}_{2}}$ from $1.62 \times 10^{-25}$ to $2.36 \times 10^{-22} \mathrm{MPa}$. According to Fig. 2 , it can be concluded 


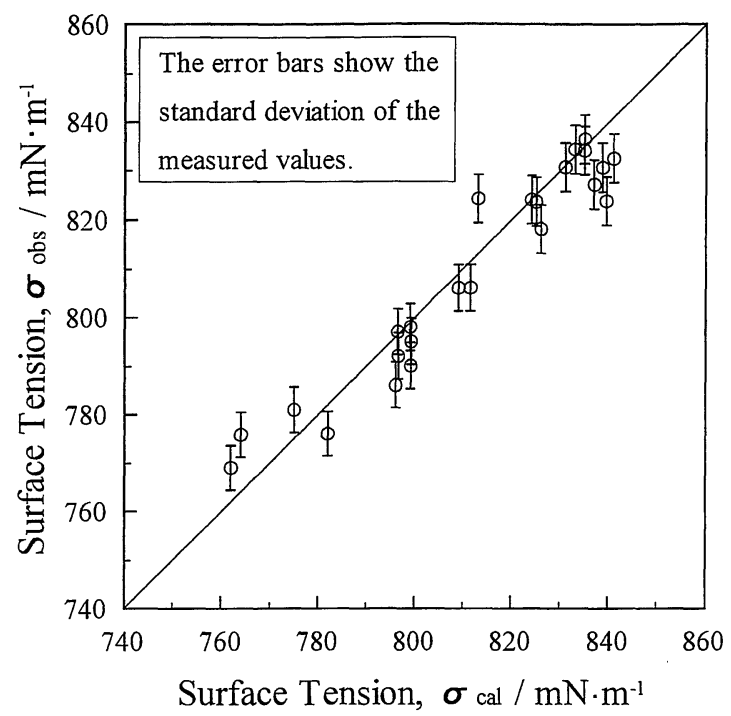

Fig. 8 Comparison of the measured values with the calculated values of the surface tension of $\mathrm{Si}-\mathrm{B}-\mathrm{O}$ system at $1693 \mathrm{~K}$.

that the error of measuring data caused by the change of $P_{\mathrm{O}_{2}}$ during this experiment is smaller than $0.8 \%$.

Equation (2) is available for describing the surface tension of $\mathrm{Si-O}$ system and is given by eq. (8). ${ }^{6}$ )

$$
\sigma=845-29.7 \ln \left(1+6.62 \times 10^{10} P_{\mathrm{O}_{2}}^{1 / 2}\right), \quad 1693 \mathrm{~K}
$$

Then, the surface tension of the present $\mathrm{Si}-\mathrm{O}-\mathrm{B}$ system may be described by simply combining eqs. (4) and (8), as shown with eq. (9), because the oxygen concentration is very small and the boron is not so strong surface active for molten silicon.

$$
\begin{aligned}
\sigma= & 845-29.7 \ln \left(1+6.62 \times 10^{10} P_{\mathrm{O}_{2}}^{1 / 2}\right) \\
& +6.37 \ln \left(1+4.49 C_{\underline{B}}\right) \quad 1693 \mathrm{~K}
\end{aligned}
$$

The values of surface tension of the experimental measurements and those calculated from eq. (9) are shown in Fig. 8. It can seen that the values calculated from eq. (9) is the same or similar to the measured values. Ogino et al. ${ }^{16)}$ have reported that the similar treatment is also available for $\mathrm{Fe}-\mathrm{O}-\mathrm{S}$ system in the dilute concentration of oxygen and sulfur.

\subsection{Contamination by the $\mathrm{BN}$ substrate}

When using the sessile drop method to measure the surface tension, the main contamination is from the substrate directly contacting molten silicon.

In order to investigate the interfacial properties between molten silicon and solid materials and also to find a suitable substrate for the surface tension measurement with the sessile drop method, wettability and reactivity between molten silicon and various kind of plates were investigated under precisely controlled the oxygen partial pressure. The oxide plates, such as $\mathrm{SiO}_{2}, \mathrm{Al}_{2} \mathrm{O}_{3}, \mathrm{MgO}, \mathrm{CaO}, \mathrm{ZrO}_{2}-\mathrm{Y}_{2} \mathrm{O}_{3}, \mathrm{ZrO}_{2}-$ $\mathrm{CaO}$ and the carbide plate $(\mathrm{SiC})$ considerably react with molten silicon and also show the good wettability, which indicates that those plates are unsuitable for the surface tension measurement. The $\mathrm{BN}$ plate is regarded to be the most suitable substrate because the $\mathrm{BN}$ has large contact angle $\left(145 \pm 5^{\circ}\right)$ and shows low chemical reactivity with molten sil-

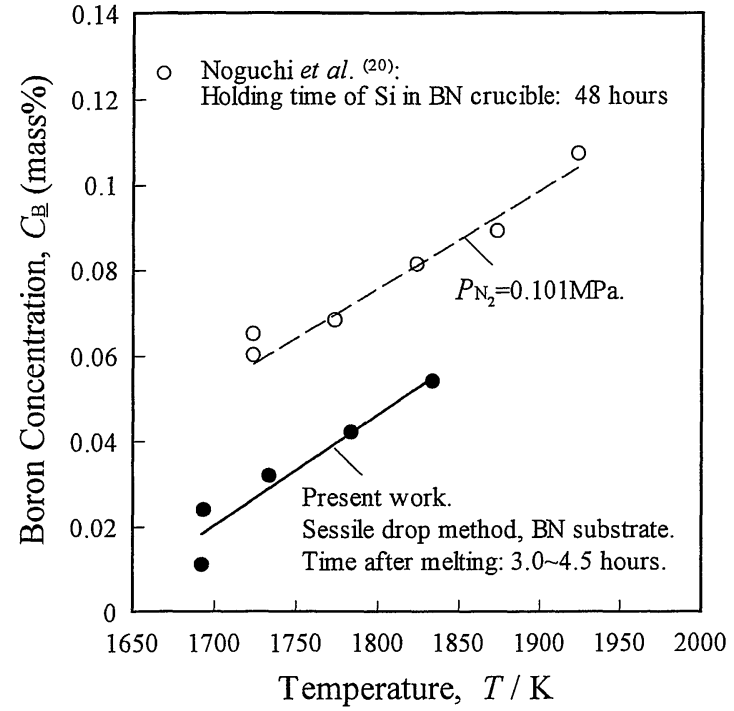

Fig. 9 Relation between temperature and boron concentration in silicon determined by ICP.

icon. The $\mathrm{Si}_{3} \mathrm{~N}_{4}$ plate shows the least reactivity with molten silicon among the all kinds of materials investigated, but it has the contact angle about $90^{\circ}$, which causes large error in the surface tension measurement. Therefore, The BN was selected as the substrate for supporting the silicon drop in the present study.

It is very difficult to split the silicon drop after the measurement from the $\mathrm{BN}$ substrate at room temperature. After the measurement, the cross section of $\mathrm{Si} / \mathrm{BN}$ interface was examined by an EPMA to know the reactivity at the interface of silicon and the BN substrate. It was confirmed that there was extreme trace of silicon in the BN side. However, in the silicon phase near the interface, it could be only confirmed the existence of $\mathrm{N}$ and it could not be confirmed the existence of boron. Therefore, it is inferred that a discontinuous $\mathrm{Si}_{3} \mathrm{~N}_{4}$ layer is possibly formed at the interface, which restricts $\mathrm{BN}$ dissolving and spreading into molten silicon after the formation of the discontinuous $\mathrm{Si}_{3} \mathrm{~N}_{4}$ layer.

Figure 9 shows $C_{\underline{\mathrm{B}}}$ of the silicon drop after measurement and the results of molten silicon in the $\mathrm{BN}$ crucible after equilibrium experiment for 48 hours. $^{20)} C_{\underline{B}}$ of $\mathrm{CZ}$ silicon sample (before measurement) was less than 1 mass ppm. After measurement, $C_{\underline{B}}$ in silicon drop without boron addition gradually increased as temperature increased. The maximum $C_{\underline{B}}$ dissolved from the $\mathrm{BN}$ substrate into molten silicon was 0.054 mass $\%$ in this study. The broken line in Fig. 9 indicates that even the reaction reaches equilibrium state, the maximum $C_{\underline{\mathrm{B}}}$ at $1873 \mathrm{~K}$ is only 0.089 mass\%. According to Fig. 4, the maximum increment of the surface tension is about $30 \mathrm{mN} \cdot \mathrm{m}^{-1} \cdot\left(\operatorname{mass} \% C_{\mathrm{B}}\right)^{-1}$ in the range of dilute boron concentration. Hence the maximum surface tension increment by $C_{\underline{B}}$ dissolved from the $\mathrm{BN}$. substrate into molten silicon is below $1.5 \mathrm{mN} / \mathrm{m}$, which shows that the influence by the $\mathrm{BN}$ substrate is much lower then the maximum error evaluated as $\pm 2 \%$ for this measurement.

\subsection{Effect of $C_{\underline{\mathrm{C}}}$ on the surface tension}

Figure 10 shows the relation between the surface tension of 


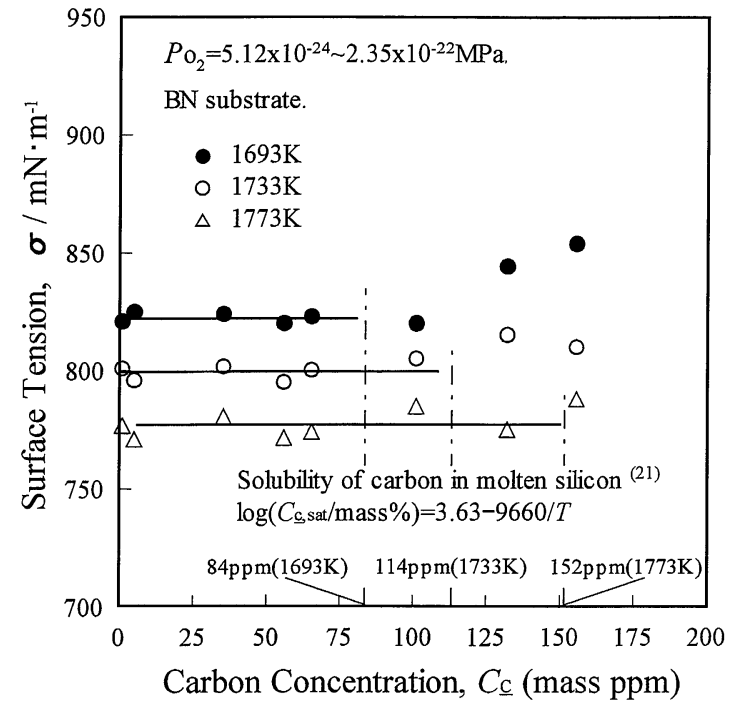

Fig. 10 Effect of carbon concentration on the surface tension of molten silicon.

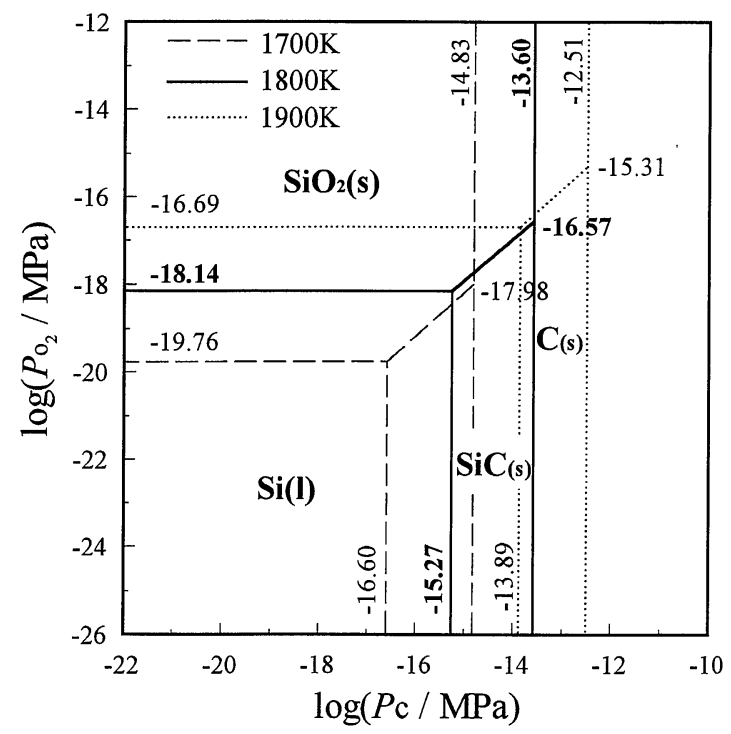

Fig. 11 Phase diagram of the condensed phases at the $\mathrm{Si}-\mathrm{O}-\mathrm{C}$ system.

molten silicon and $C_{\underline{C}}$ in the range of $P_{\mathrm{O}_{2}}$ from $5.12 \times 10^{-24}$ to $2.35 \times 10^{-22} \mathrm{MPa}$. The surface tension of molten silicon remains almost constant even in carbon saturated sili$\operatorname{con}\left(\log C_{\mathrm{c}, \mathrm{sat}}=3.63-9660 / T\right.$, mass $\left.\%\right) .{ }^{21)}$ Figure 11 shows phase diagram of the condensed phases at the Si-O-C system and is drawn from thermodynamic data. ${ }^{22)}$ The point $P_{\mathrm{c}, \text { sat }}$ at the co-existing line of $\mathrm{Si}(\mathrm{l})$ and $\mathrm{SiC}(\mathrm{s})$ is corresponding to the saturated carbon concentration in molten silicon $\left(C_{\underline{\mathrm{c}} \text {,sat }}\right)$. When the partial pressure $P_{\mathrm{c}}$ is larger than or equal to $P_{\mathrm{c} \text {,sat }}$, the silicon drop is in the condition that a $\mathrm{SiC}(\mathrm{s})$ film can be formed on the surface of molten silicon drop, which may cause the increase in the surface tension of molten silicon in the range of $P_{\mathrm{c}}>P_{\mathrm{c}, \text { sat }}$ as shown in Fig. 10. Figure 12 shows the relation between the temperature coefficient of the surface tension, $K^{\mathrm{C}}=(\partial \sigma / \partial T)_{C_{\underline{\mathrm{C}}}}$, and carbon concentration in silicon. $C_{\underline{C}}$ has almost no influence on the temperature coefficient of the surface tension in the range of $C_{\mathrm{C}} \leqq 84$ mass ppm

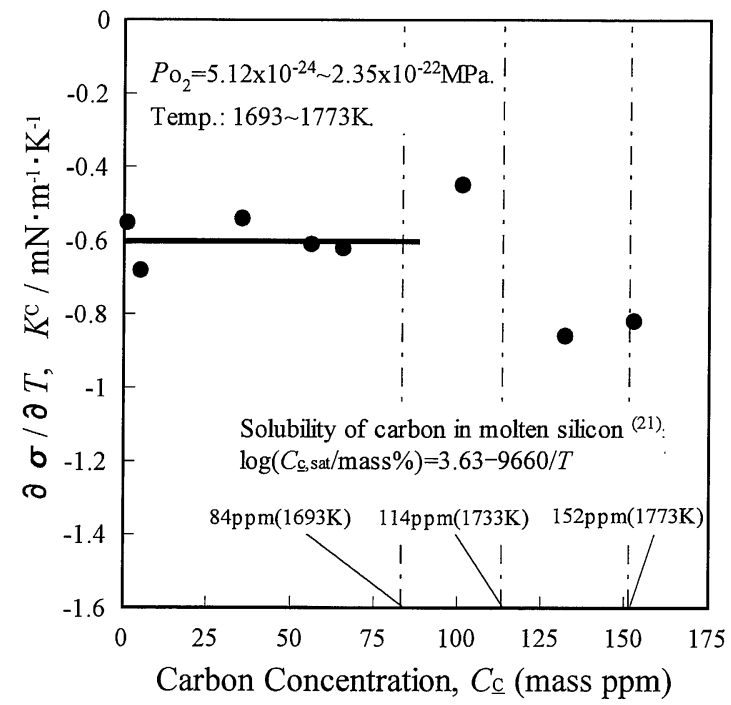

Fig. 12 Relation between temperature coefficient of the surface tension and carbon concentration in silicon.

$\left(C_{\underline{\mathrm{c}}, \text { sat }}\right.$ at $\left.1693 \mathrm{~K}\right)$.

\section{Conclusions}

The effects of boron concentration $\left(C_{\underline{B}} /\right.$ mass $\left.\%\right)$ and carbon concentration $\left(C_{\underline{C}} /\right.$ mass $\left.\%\right)$ on the surface tension of molten silicon have been determined with the sessile drop method under precisely controlled the oxygen partial pressure in the range of $P_{\mathrm{O}_{2}} \leqq 10^{-22} \mathrm{MPa}$.

(1) The change of surface tension of molten silicon is very small in the range of $P_{\mathrm{O}_{2}} \leqq 10^{-22} \mathrm{MPa}$. The temperature coefficient of the surface tension, $(\partial \sigma / \partial T)_{P_{\mathrm{O}_{2}}}$, increases with increasing $P_{\mathrm{O}_{2}} . \quad(\partial \sigma / \partial T)_{P_{\mathrm{O}_{2}}}$ is equal to about $-0.75 \mathrm{mN} \cdot \mathrm{m}^{-1} \cdot \mathrm{K}^{-1}$ at $P_{\mathrm{O}_{2}}=10^{-24} \mathrm{MPa}$ and then $(\partial \sigma / \partial T)_{P_{\mathrm{O}_{2}}}$ gradually increases with increasing the oxygen partial pressure up to $5 \times 10^{-22} \mathrm{MPa}$. $(\partial \sigma / \partial T)_{P_{\mathrm{O}_{2}}}$ steeply increases with increasing the oxygen partial pressure in argon gas in the range of $P_{\mathrm{O}_{2}}$ from $5 \times 10^{-22}$ to $10^{-20} \mathrm{MPa}$.

(2) The surface tension increases with increasing $C_{\underline{B}}$, which shows negative adsorption of boron, and the maximum increase rate of the surface tension is about $30 \mathrm{mN} \cdot \mathrm{m}^{-1} \cdot\left(\operatorname{mass} \% C_{\underline{B}}\right)^{-1}$ in the range of dilute boron concentration. The relation between the surface tension and $C_{\underline{B}}$ is fairly well described with Szyszkowski's equation. $(\partial \sigma / \partial T)_{C_{\underline{B}}}$ also increases with increasing boron concentration.

(3) Since dissolved boron from the $\mathrm{BN}$ substrate into molten silicon is below 0.054 mass $\%$ and the associated increase of the surface tension is below $1.5 \mathrm{mN} / \mathrm{m}$, the contamination from the $\mathrm{BN}$ substrate on the surface tension can be ignored.

(4) The surface tension of molten silicon remains almost constant even in carbon saturated silicon and $C_{\underline{\mathrm{C}}}$ has almost no influence on $(\partial \sigma / \partial T)_{C_{\mathrm{C}}}$ in the range of $\bar{C}_{\underline{\mathrm{C}}} \leqq$ 84 mass ppm $\left(C_{\underline{\mathrm{c}} \text {,sat }}\right.$ at $\left.1693 \mathrm{~K}\right)$. 


\section{Acknowledgments}

This work is the results of "Technology for Production of High Quality Crystal" which is supported by the New Energy and Industrial Technology Development Organization (NEDO) through the Japan Space Utilization Promotion Center (JSUP) in the program of the Ministry of International Trade and Industry (MITI).

\section{REFERENCES}

1) K. G. Barraclough: J. Crystal Growth, 99 (1990), 654-659.

2) T. Narushima, K. Matsuzawa, M. Mamiya and Y. Iguchi: Mater. Trans., JIM, 36 (1995), 763-769.

3) Y. Shimanuki, H. Furuya and I. Suzuki: J. Electrochem. Sec., 136 (1989), 2058-2062.

4) K. Yanaba, Y. Matsumura, T. Narushima and Y. Iguchi: Mater. Trans., JIM, 39 (1998), 819-823.

5) K. Mukai and Z. Niu: J. Jpn. Assoc. Crystal Growth, 23 (1996), 93-99.

6) Z. Niu, K. Mukai, Y. Shiraishi, T. Hibiya, K. Kakimoto and M. koyama: J. Jpn. Assoc. Crystal Growth, 24 (1997), 369-378.

7) Y. Rotenberg, L. Boruvka and A. W. Neumann: J. Colloid Interface Sci., 93 (1983), 169-183.
8) K. Mukai and Z. Yuan: Mater. Trans., JIM, 41 (2000), 323-330.

9) N. Shinozaki, M. Sonoda and K. Mukai: Metall. and Mater. Trans., 29A (1998), 1121-1125.

10) Z. Niu, K. Mukai, Y. Shiraishi, T. Hibiya, K. Kakimoto and M. koyama: J. Jpn. Assoc. Crystal Growth, 23 (1996), 374-381.

11) T. Narushima, K. Matsuzawa, Y. Mukai and Y. Iguchi: Mater. Trans., JIM, 35 (1994), 522-528.

12) R. W. Olesinski and G. J. Abbaschian: Binary Alloy Phase Diagrams, Vol. 1, ed. by T. B. Massalski, American Society for Metals, (1986), pp. 384-395.

13) B. J. Keene: Surface and Interface Analysis, 10 (1987), 367-383.

14) B. V. Szyszkowski: Z. Phys. Chem., 64 (1908), 385-389.

15) G. R. Belton: Metall. Trans., 7B (1976), 35-42.

16) K. Ogino, K. Nogi and C. Hosoi: Tetsu-to-Hagane, 69 (1983), 19891994.

17) N. Takeuchi, T. Taniguchi, N. Shinozaki and K. Mukai: J. Japan Inst. Metals, 55 (1991), 44-49.

18) J. Zhu and K. Mukai: ISIJ International, 38 (1998), 1039-1044.

19) K. Monma and H. Suto: J. Japan Inst. Metals, 24 (1960), 163-167.

20) R. Noguchi, K. Suzuki, F. Tsukihashi and N. Sano: Metall. Mater. Trans., 25B (1994), 903-907.

21) K. Yanaba, M. Akasaka, M. Takeuchi, M. Watanabe, T. Narushima and Y. Iguchi: Mater. Trans., JIM, 38 (1997), 990-994.

22) D. R. Stull and H. Prophet: JANAF Thermochemical Tables, Second ed., National Bureau of Standards, Washington, (1971), pp. 1110-1115. 